\title{
O estágio de docência na Licenciatura em Educação do Campo - Ciências da Natureza: um panorama a partir dos espaços educativos escolares
}

\author{
Practical Training in Fieldwork in the Natural Sciences in a \\ Teacher Accreditation Course: an overview based on school spaces
}

\author{
Brenda Sarmiento de Andrade (brendasarmiento97@gmail.com) \\ Universidade Federal do Rio Grande do Sul (UFRGS)/Faculdade de Educação (FACED)/ \\ Licenciatura em Educação do Campo \\ Bruna Sarmiento de Andrade (brunasarmiento@gmail.com) \\ Universidade Federal do Rio Grande do Sul (UFRGS)/Faculdade de Educação (FACED)/ \\ Licenciatura em Educação do Campo \\ Marilisa Bialvo Hoffmann (marilisa.ufrgs@ gmail.com) \\ Universidade Federal do Rio Grande do Sul (UFRGS)/Faculdade de Educação (FACED)/ \\ Licenciatura em Educação do Campo \\ Saul Benhur Schirmer (sschirmer@gmail.com) \\ Universidade Federal do Rio Grande do Sul (UFRGS)/Faculdade de Educação (FACED)/ \\ Licenciatura em Educação do Campo
}

Resumo: O presente artigo é resultante de um Trabalho de Conclusão no Curso de Licenciatura em Educação do Campo - Ciências da Natureza da Universidade Federal do Rio Grande do Sul (UFRGS) campus Porto Alegre. Investigou-se o perfil acadêmico, os desafios e as possibilidades acerca da formação docente presentes nos municípios atendidos pela Licenciatura em Educação do Campo - Ciências da Natureza (EduCampo). Para tanto, o estudo foi organizado em três etapas: levantamento dos locais de abrangência e de efetiva atuação do curso; levantamento e organização dos dados referentes às escolas e professores/as dos locais onde são realizados os estágios de docência; e realização de entrevista com alguns professores/as supervisores de estágio nas escolas. Após a análise, os resultados demonstram as potencialidades e a necessidade de articulações os territórios de abrangência do curso; a demanda de reconhecimento do curso na região metropolitana; e a importância de uma formação de professores/as por área de conhecimento em Ciências da Natureza voltada para as especificidades do campo.

Palavras-chave: Educação do Campo, Ensino de Ciências, Formação de professores, Estágio de Docência.

Abstract: This article is based on a final course project in a teacher accreditation course
in fieldwork in the natural sciences at the Federal University at Rio Grande do Sul
(UFRGS), at the Porto Alegre campus. The project investigated the academic profile,
challenges and opportunities related to teacher education found in municipalities served
by the program for accreditation in fieldwork for natural sciences teachers (EduCampo).
The study was organized in three phases: a survey of the locations encompassed by and
the effective action of the program; a survey and organization of data about the schools
and teachers at the locations where the teaching training takes place; and interviews with
teachers and supervisors of teacher training in the schools. After the analysis, the results
reveal the potentials and need for articulations among the territories encompassed by the 
course; the demand for recognition of the course in the metropolitan region; and the importance of training teachers in the natural sciences for the specificities of fieldwork.

Keywords: Education in the field, Science Education, Teacher education, Teacher training.

\section{INTRODUÇÃ̃O}

A proposta de formação docente a partir das Licenciaturas em Educação do Campo como política pública do Ministério da Educação (MEC), teve início no ano de 2007 com quatro experiências-piloto desenvolvidas pelas Universidade Federal de Minas Gerais (UFMG), Universidade de Brasília (UnB), Universidade Federal de Sergipe (UFS) e Universidade Federal da Bahia (UFBA), mediante a criação do Programa de Apoio à Formação Superior em Licenciatura em Educação do Campo (PROCAMPO). Tal política foi construída como resultado de uma intensa reivindicação dos trabalhadores rurais, que já pautavam a necessidade de um sistema específico de formação de educadores, desde a realização da II Conferência Nacional de Educação do Campo realizada em 2004. Em 2012, a partir da luta dos movimentos sociais do campo, foram conquistados 42 cursos permanentes dessa nova graduação em todas as regiões do país. Objetivando garantir a implementação dos cursos, o Ministério da Educação disponibilizou 600 vagas de concurso público de docentes da Educação Superior e 126 vagas de técnicos como suporte para esse processo (MOLINA, 2017).

A Universidade Federal do Rio Grande do Sul (UFRGS) participou deste processo, implantando a Licenciatura em Educação do Campo - Ciências da Natureza (EduCampo/UFRGS) em 2013, com o objetivo de formar licenciados para atuação na docência em Ciências da Natureza e na gestão de escolas do campo, em articulação com os espaços não-escolares das comunidades, abrangendo um total de 77 municípios da região metropolitana de Porto Alegre-RS. De acordo com o Projeto Pedagógico do Curso - PPC (UFRGS, 2013), e respondendo às orientações básicas propostas pelo Edital 02/2012 SECADI/SESU/SETEC - MEC, a EduCampo/UFRGS propõe-se a:

a) Considerar a perspectiva da interdisciplinaridade, a qual se caracteriza como uma estratégia de integração metodológica, seja para fins tecnológicos, epistemológicos, 
ou pedagógicos, podendo gerar novos campos de conhecimento, ou procedimentos inovadores para responder a novas necessidades sociais.

b) Organizar os componentes curriculares em áreas do conhecimento de forma interdisciplinar com ênfase nas Ciências da Natureza, de modo que os estudantes possam vivenciar na prática de sua formação a lógica do trabalho pedagógico para o qual estão sendo preparados.

c) Organizar metodologicamente o currículo por alternância entre Tempo/Espaço-Universidade e Tempo/Espaço-Comunidade, de modo a permitir o necessário diálogo entre saberes técnico-tecnológicos e saberes das tradições culturais oriundos das experiências de vida no campo.

Passados cinco anos da implantação do curso na UFRGS é fundamental realizar um balanço da inserção deste nas comunidades, com o objetivo de (re)conhecer os territórios de atuação e de levantar as demandas e desafios, tendo em vista a consolidação do mesmo na Universidade e na comunidade. Para tanto, este estudo propôs-se a responder à seguinte questão: Qual o panorama dos estágios de docência da EduCampo/UFRGS, a partir dos espaços escolares? Esta questão, por sua vez, desdobrou-se eu outras, como: 1) Em que escolas, níveis e séries de ensino a EduCampo/UFRGS atua através dos estágios de docência? 2) Qual a compreensão dos professores supervisores de estágios das escolas, sobre a EduCampo? 3) Quais demandas emergem do conhecimento desta realidade? 4) Que espaços não-escolares são contemplados neste contexto de realização dos estágios?

Desse modo, objetivou-se, entre outros, a produção coletiva e aplicação de instrumentos qualitativos para o mapeamento e organização de um banco de dados dos espaços de atuação do curso. Investigou-se, também, o conhecimento em torno do perfil, formação, desafios e possibilidades acerca da formação docente presentes nos municípios e que a EduCampo/UFRGS encontra-se inserida através dos estágios de docência.

\section{EDUCAÇÃO DO CAMPO E FORMAÇÃO DE PROFESSORES/AS DE CIÊNCIAS}


Munarim (2008), descreve que é arriscado afirmar que exista um movimento lapidado da Educação do Campo no Brasil. Para o autor há um movimento nascente, de conteúdo político e pedagógico, que vem sendo construído por sujeitos relacionados com as questões agrárias, ou seja, um movimento que ainda está em construção. A Licenciatura em Educação do Campo é um curso novo de graduação que vem sendo estruturado em instituições de Ensino Superior no Brasil desde 2007, com apoio do MEC, voltados preferencialmente para educadores/as do campo (CALDART, 2011). Ao avaliar os dez anos de caminhada das Licenciaturas em Educação do Campo no Brasil, Caldart (2017), enfatiza que a força da Educação do Campo se mostra pela consciência de suas raízes: vínculo com os movimentos sociais camponeses e trabalhadores do campo; relação orgânica com o trabalho no campo e na diversidade de seus sujeitos; e compromisso com determinada concepção de educação que visa à emancipação dos sujeitos.

A criação desta nova modalidade de Licenciatura, é resultado da luta dos movimentos sociais e sindicais que depois de dez anos de luta, finalmente conquistam uma política de formação inicial para educadores/as do campo, vinculada pela primeira vez ao MEC, a partir da criação do Programa de Apoio à Formação Superior em Licenciatura em Educação do Campo - PROCAMPO (MOLINA, 2014). Nesse sentido, é necessário que a formação de educadores/as que estão sendo preparados/as para atuar nas escolas do campo considere que a permanência e a existência (tanto das escolas, quanto dos sujeitos) passam “pelos caminhos que se trilharão a partir dos desdobramentos da luta de classes, do resultado das forças em disputa na construção dos distintos projetos de campo na sociedade brasileira" (MOLINA, 2014, p. 12).

De acordo com Molina (2014), a partir da perspectiva da formação docente multidisciplinar, a matriz curricular das Licenciaturas em Educação do Campo propõe organização dos componentes curriculares em quatro áreas do conhecimento: Linguagens (expressão oral e escrita em Língua Portuguesa, Artes, Literatura); Ciências da Natureza e Matemática; Ciências Humanas e Sociais; e Ciências Agrárias. Trata-se, portanto, de promover a organização de novos espaços curriculares que articulam componentes tradicionalmente disciplinares, por meio de uma abordagem ampliada de conhecimentos científicos que dialogam entre si a partir de recortes da realidade complementares, 
buscando pontuar a práxis quanto à formação de professores/as por área de conhecimentos e não a fragmentação disciplinar.

A formação por área de conhecimento; a interdisciplinaridade; a alternância entre Tempo-Comunidade e Tempo-Universidade compõe o conjunto de elementos que definem as diretrizes da Licenciatura em Educação do Campo (CALDART, 2011). Com isso, buscou-se aqui a proposição de reflexões e diálogos entre as diretrizes da Educação do Campo para a formação de professores/as juntamente com suas práticas pedagógicas nas escolas e comunidades do campo.

A Licenciatura em Educação do Campo da Universidade Federal do Rio Grande do Sul (UFRGS) do campus Porto Alegre propõe-se atender a uma nova demanda, as populações do campo, que historicamente lutam por uma educação diferenciada e de qualidade, que respeite as especificidades da vida neste contexto, de acordo com o seu Projeto Pedagógico de Curso - PPC (2013). Assim, é previsto que as disciplinas do curso ocorram de modo articulado nas diversas temáticas abordadas contemplando os conhecimentos específicos das Ciências Naturais (Química, Física e Biologia), de aspectos da Matemática e das Ciências Agrárias (PPC, 2013). Nessa perspectiva, a formação na área de Ciências da Natureza, fomenta que os conhecimentos/conteúdos serão estudados a partir de situações reais de cada sujeito, organizadas por eixos temáticos, definidos para cada ano, e temas geradores, definidos para cada semestre.

A formação por área de conhecimento vem sendo trabalhada nas Licenciaturas em Educação do Campo que, nesse sentido, se ancora no projeto de construção de uma escola que considere a cultura local e que compreenda os saberes construídos a partir das experiências de vida desses sujeitos, buscando uma prática pedagógica que atenda as peculiaridades no/do campo (CALDART, 2011).

Entende-se, portanto, que a adoção de uma formação docente interdisciplinar e por área, no âmbito do campo, propõe uma compreensão da realidade socioeconômica de cada localidade e que cada área de ensino contribui para esse processo de ensinoaprendizagem. Levando em consideração o Decreto n ${ }^{\circ} 7.352 / 2010$, a Escola do Campo é aquela situada em área rural, conforme dados do Instituto Brasileiro de Geografia e Estatística (IBGE) ou em área urbana, desde que atenda predominantemente a populações do campo. Também, na Resolução no 2/2008, consta no artigo 5, os incisos 1 e 2, vide: 
$\S 1^{\circ}$ A organização e o funcionamento das escolas do campo respeitarão as diferenças entre as populações atendidas quanto à sua atividade econômica, seu estilo de vida, sua cultura e suas tradições.

$\S 2^{\circ} \mathrm{A}$ admissão e a formação inicial e continuada dos professores e do pessoal de magistério de apoio ao trabalho docente deverão considerar sempre a formação pedagógica apropriada à Educação do Campo e às oportunidades de atualização e aperfeiçoamento com os profissionais comprometidos com suas especificidades.

Conforme dados da Secretaria Estadual de Educação do Estado do Rio Grande do Sul (SEDUC/RS, 2017), o Censo Escolar de 2015 aponta que das 2,5 mil escolas da Rede Estadual 657 são identificadas como Escolas do Campo/Rurais. Entre elas estão 90 escolas indígenas e 35 escolas de assentamentos. A partir de 2012, através do Decreto 49.861/2012, instituiu-se o Comitê Estadual de Educação do Campo do Estado do Rio Grande do Sul, com caráter colaborativo na formulação, implementação e acompanhamento das políticas de educação do campo.

Além disso, de acordo com o Plano Estadual de Educação do Estado do Rio Grande do Sul (Lei № 14.705/2015), cabe ao Estado desenvolver currículos e propostas pedagógicas específicas para educação escolar para as escolas do/no campo, além de:

Expandir o atendimento do ensino médio gratuito com qualidade social para as populações do campo, para as comunidades indígenas e quilombolas, respeitando as suas características, interesses e necessidades. (Rio Grande do Sul, 2015, p.13)

O PPC (2013) da EduCampo/UFRGS prevê para o egresso a habilitação para desenvolver projetos pedagógicos interdisciplinares na área de Ciências da Natureza em espaços educativos escolares e não escolares. Também, o licenciado nesta área estará apto para atuar na disciplina de Ciências, Biologia, Química e Física nas diferentes modalidades de ensino (Ensino Fundamental, Ensino Médio e Educação de Jovens e Adultos) e, além destas, em instituições que desenvolvam modalidades de assistência técnica e extensão rural.

Nesse sentido, conforme o PPC (2013), a Licenciatura em Educação do Campo embasa a formação por área de conhecimento em Ciências da Natureza, como um projeto que articula com todas as etapas e modalidades da Educação Básica, buscando preparar educadoras(es) para a atuação profissional que vá além da docência e que dialoguem com os diferentes espaços educativos das comunidades. Atualmente, a EduCampo/UFRGS campus Porto Alegre tem sua área de atuação abrangendo 77 municípios. 
A formação por área de conhecimento se insere num esforço de afirmação da Educação do Campo como política pública, relacionando o curso com a construção de um sistema público de educação para as escolas do campo (PPC, 2013), levando em consideração que campo é território de produção de vida, de produção de novas relações sociais, de novas relações entre os homens e a natureza, de novas relações entre o rural e o urbano.

\section{PERCURSO METODOLÓGICO}

A investigação teve cunho qualitativo (LUDKE; ANDRÉ, 2013) e se organizou, metodologicamente, em quatro etapas: a) Levantamento dos locais de abrangência e de efetiva atuação do curso EduCampo/UFRGS; b) Construção do banco de dados dos Estágios de Docência; c) Realização de Entrevista semi-estruturada com supervisores de estágio das escolas; d) Análise das entrevistas.

Na primeira etapa, realizou-se um levantamento dos locais de abrangência e de efetiva atuação do curso EduCampo/UFRGS, com foco nos Tempos-Comunidade nos anos de 2017, 2018 e 2019/1. Este recorte temporal foi estipulado no intuito de reconhecer os espaços educativos a partir da realização dos estágios de docência obrigatórios, que começaram a ser efetivados a partir de 2017.

Com este critério, conseguiu-se abarcar, na presente pesquisa, as duas primeiras turmas da EduCampo/UFRGS e, respectivamente, os três estágios de docência realizados na sua integralidade (um de Ensino Fundamental e dois do Ensino Médio) na primeira e na segunda turma do curso. Foram organizados os territórios que são de abrangência da EduCampo/UFRGS, especificando em quais municípios o curso já se encontra inserido, as escolas em que são realizadas ações do curso e os diversos espaços não-escolares nos quais a EduCampo/UFRGS realiza intervenções educativas através dos estágios. Embora o foco deste estudo sejam os espaços escolares, acredita-se que a identificação dos espaços não-escolares é necessária para uma melhor compreensão da dinâmica pedagógica do estágio no curso, que abrange obrigatoriamente a interlocução entre ambos os espaços.

A partir disso, obteve-se, em diálogo com os colegas estagiários e consulta 
documental, mais dados sobre as escolas: a localização, turmas em que os estágios foram realizados, formação do professor supervisor, entre outros. Isso possibilitou a obtenção de uma panorama geral sobre os locais de realização dos estágios de docência da EduCampo, que foram organizados em forma de gráficos. Considera-se de suma importância o conhecimento destes locais e suas peculiaridades, visto que em sua maioria, são escolas que já realizam um trabalho integrado à EduCampo desde os primeiros semestres do curso. Conhecer as necessidades e demandas, expectativas, bem como o perfil dos docentes que recebem os estagiários auxilia em muito para futuras ações do curso.

$\mathrm{Na}$ terceira etapa, realizaram-se entrevistas semi-estruturadas com seis professores/as supervisores dos estágios, sendo três do Ensino Fundamental e três do Ensino Médio. Os critérios para seleção foram a acessibilidade e disponibilidade para realização das entrevistas. O objetivo foi o de conhecer melhor estes docentes, suas demandas e suas compreensões em torno da Educampo e seus egressos. Vale ressaltar que as realizações das entrevistas se deram mediante a participação voluntária e após assinado o Termo de Consentimento Livre e Esclarecido (TCLE). As(os) entrevistadas(os) foram nomeadas(os) como E1, E2, E3, E4, E5 e E6 para se manter o sigilo da pesquisa.

A entrevista foi guiada por um roteiro de questões, que aborda informações relativas a: dados da escola; dados pessoais; aspectos da formação profissional; e aspectos relativos à Educação do Campo/Ciências da Natureza. A realização do estudo piloto ou “entrevista piloto" é denominada por Manzini (2003) como uma etapa de adequação do roteiro construído para a entrevista. A partir do roteiro previamente construído, realizouse uma entrevista-piloto com uma professora do Ensino Fundamental e Médio, também supervisora de estágio obrigatório da EduCampo. Suas análises contribuíram para a validação das questões e possíveis adequações do roteiro. As questões foram definidas de acordo com uma adaptação de Hoffmann (2016) às proposições de Manzini (2003) sobre entrevistas semi-estruturadas, identificando para cada questão e/ou tópico da entrevista, uma intenção/ação verbal. Dessa maneira, cada etapa do roteiro pode se desdobrar em outras questões ou diálogos, mas o foco principal não se perde, que é de responder à intenção já previamente delimitada. 
Quadro 1: Análise do roteiro de entrevista

\begin{tabular}{|c|c|}
\hline Questão e/ou tópico & Intenções/ação verbal \\
\hline $\begin{array}{l}\text { Nome, Idade, Formação acadêmica, tempo de } \\
\text { atuação na escola, número de horas trabalhadas } \\
\text { na escola do estágio e número de escolas em que } \\
\text { trabalha }\end{array}$ & $\begin{array}{l}\text { - Identificar aspectos gerais da carreira } \\
\text { profissional. }\end{array}$ \\
\hline $\begin{array}{l}\text { Como se vê sendo supervisor(a) de um } \\
\text { estagiário(a) da Licenciatura em Educação do } \\
\text { Campo/ }\end{array}$ & $\begin{array}{l}\text { - } \quad \text { Identificar a compreensão sobre o curso; } \\
\text { - } \quad \text { Analisar o papel da supervisão do estágio para a } \\
\text { formação do docente e do(a) licenciando (a). }\end{array}$ \\
\hline $\begin{array}{l}\text { Como costuma ser a relação com os alunos(as) } \\
\text { estagiários(as)? }\end{array}$ & $\begin{array}{l}\text { - Analisar o papel da supervisão do estágio para a } \\
\text { formação do docente e do(a) licenciando (a). }\end{array}$ \\
\hline $\begin{array}{l}\text { Qual seu conhecimento sobre a Licenciatura em } \\
\text { Educação do Campo? }\end{array}$ & - $\quad$ Identificar a compreensão sobre o curso. \\
\hline $\begin{array}{l}\text { Como visualiza a relação da escola e da sua } \\
\text { prática com os espaços não-escolares da } \\
\text { comunidade? }\end{array}$ & $\begin{array}{l}\text { - } \quad \text { Identificar a compreensão sobre o curso; } \\
\text { - Compreender as relações que a escola já } \\
\text { estabelece com a comunidade e quais iniciaram a } \\
\text { partir do estágio. }\end{array}$ \\
\hline $\begin{array}{l}\text { Em sua experiência docente, já orientou estágios } \\
\text { que fizessem essa interlocução entre escola e } \\
\text { comunidade? }\end{array}$ & $\begin{array}{l}\text { - } \quad \text { Identificar a compreensão sobre o curso; } \\
\text { - Analisar o papel da supervisão do estágio para a } \\
\text { formação do docente e do(a) licenciando (a). } \\
\text { - Compreender as relações que a escola já } \\
\text { estabelece com a comunidade e quais iniciaram a } \\
\text { partir do estágio. }\end{array}$ \\
\hline
\end{tabular}

Fonte: (adaptado de MANZINI, 2003 e HOFFMANN, 2016)

\section{RESULTADOS E DISCUSSÕES}

$\mathrm{Na}$ primeira etapa da investigação, que visava o levantamento dos locais de abrangência e de efetiva atuação do curso EduCampo/UFRGS, se obteve um panorama dos espaços em que os licenciandos/as estão inseridos e, consequentemente, dos locais potencialmente formativos que a EduCampo poderia ainda, buscar articulações. 


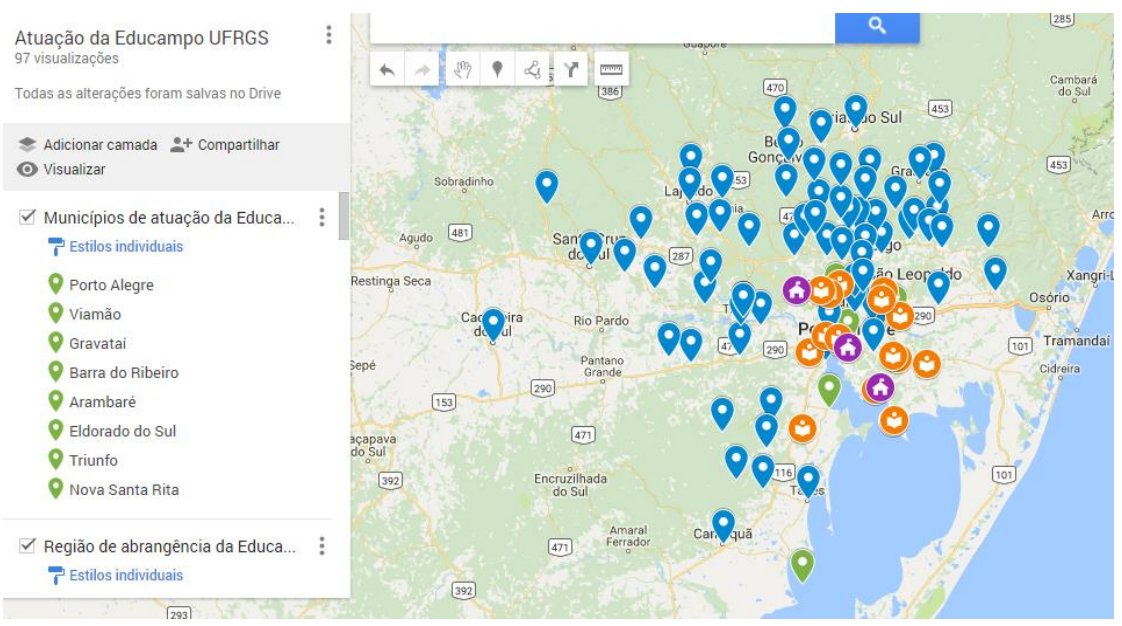

Figura 1: Mapa interativo da atuação da EduCampo/UFRGS

Fonte: dos autores, 2018.

Com auxílio do Google Maps ${ }^{\circledR}$ foi produzido um mapa on line, interativo, com os territórios de atuação da EduCampo. Neste mapa, além dos locais de atuação dos estágios, foram inseridos (para além da presente pesquisa) dados sobre o grupo de estudantes atuantes nos Tempos-Comunidade do curso bem como seus respectivos orientadores, dados sobre os territórios, fotos, entre outros. Este mapa foi incorporado ao site do curso ${ }^{1}$, como forma de acesso aos trabalhos realizados pela EduCampo, tanto pela comunidade acadêmica quanto externa à UFRGS.

Ao todo, no recorte temporal estipulado, o panorama geral dos espaços educativos escolares e não-escolares da EduCampo/UFRGS compreende 17 escolas públicas, Postos de Saúde comunitários, hortas comunitárias, propriedades rurais, Centros de Referência em Assistência Social (CRAS), Colônias de Pescadores, Secretaria do Estado do Meio Ambiente (SEMA), Bibliotecas comunitárias, Grupos de Mulheres, Confederação Nacional dos Trabalhadores na Agricultura (CONTAG), Pastorais, Museus comunitários, Empresa de Assistência Técnica e Extensão Rural (EMATER), Cooperativa de Produção Agropecuária Nova Santa Rita (COOPAN), Assentamento Itapuí e Assentamento Belo Monte, 02 escolas indígenas, 01 Comunidade quilombola. Importante ressaltar que os estágios de docência da EduCampo/UFRGS, em consonância com o previsto no perfil de egresso do curso, preveem atuação em espaços educativos

1 O mapa das imagens acima pode ser acessado no endereço <https://www.ufrgs.br/liceducampofaced/tempo-comunidade/ >. 
escolares articulados a espaços não-escolares das comunidades. De acordo com o PPC do curso:

$\S 1^{\circ}$. Conforme especificidades curriculares desta Licenciatura em Educação do Campo - Ciências da Natureza, descritas no respectivo Projeto Pedagógico do Curso (PPC) [...], cada um dos Estágios de Docência será realizado obrigatoriamente em espaços educativos escolares e não escolares no mesmo semestre. (PPC EDUCAMPO, 2013.)

Como já destacado, o foco, na presente pesquisa, não é realizar uma análise dos espaços educativos não-escolares presentes nos estágios de docência do curso. No entanto, como a atuação nestes locais são inerentes aos estágios de docência, considerouse compreender a percepção dos/as professores/as supervisores/as sobre esta necessária integração entre escola e comunidade, bem como sobre a atuação dos/as estagiários/as da EduCampo/UFRGS nestes locais. Sobre isso, a professora E1 e E5 destacaram que:

"Sempre busco fazer ligações com outras localidades e até em locais de dentro da escola mesmo, senão a educação acaba se tornando uma utopia para o aluno. Porque senão ele não consegue fazer a ligação e ele não traz esse conhecimento de casa, do cotidiano dele, do que ele tem como argumento e aí em sala de aula ele não consegue fazer isso. Agora, se o professor traz isso para a sala de aula pode tornar um estudo fácil, é uma prática, é prazeroso para o professor e para o aluno." (E1)

“Temos uma ótima relação com a nossa comunidade, a escola está sempre aberta inclusive para empréstimos para eventos onde todos são beneficiados, mas não temos projetos específicos que interliguem escola e comunidade." (E5)

Embora os/as entrevistados/as acima tenham mencionado que a escola e eles/as próprios/as buscam fazer interlocuções com espaços não-escolares da comunidade, somente o/a entrevistado/a E6 fez algum tipo de relação com os sujeitos do campo e movimentos sociais do campo:

"Entendemos que os conteúdos que a escola trabalha tem que estar vinculada a realidade da região, do entorno, enfim, procuramos sempre que possível interagir com os espaços não escolares, como seminários da agricultura camponesa, da agricultura orgânica, propriedades dos agricultores para visitas, experiências e atividades de encontros estaduais e regionais com o movimento sem terra que a comunidade faz parte." (E6)

Analisando os dados obtidos na segunda etapa desta investigação, onde levantamos dados gerais sobre os estágios de docência realizados pelas turmas 1 (estágios de Ensino Fundamental e Médio) e 2 (estágios de Ensino Fundamental e Médio), realizados no recorte temporal de 2017/2 a 2019/1, pode-se verificar, na Figura 2, a 
distribuição dos estágios obrigatórios da EduCampo/UFRGS de acordo com as redes de ensino, divididas em municipal, estadual ou particular/comunitária. Há preponderância dos estágios na rede estadual de ensino do RS (70\%) em relação às redes municipais (15\%) e particular/comunitária (15\%). Acredita-se que o maior número de escolas na rede estadual se dê em função de haver, no curso, dois estágios de Ensino Médio (ofertado preferencialmente na rede estadual) e apenas um de Ensino Fundamental.

Número de Escolas por Rede de Ensino

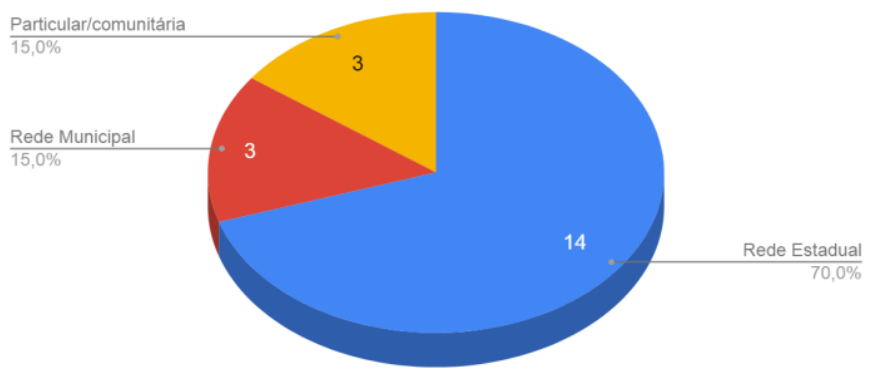

Figura 2: Número de escolas por rede de ensino Fonte: dos autores, 2019.

Em relação à rede pública de ensino, as falas dos professores/as entrevistados (E4, E5) revelam algumas particularidades, como a abertura para a recepção de estagiários e o necessário vínculo com as questões locais da comunidade:

\footnotetext{
“A educação, pelo menos a pública, anda carente de profissionais e estagiários sempre trazem uma energia nova." (E5,)

"Eu acho uma troca muito importante, porque isso desafia, nós professores, a modificar as aulas. E ter estagiários nas aulas desacomoda um pouco o alunos e faz com que eles nos cobram mais as coisas e acho que isso é muito bom até para esse nosso contexto. Às vezes, nós temos uma desmotivada e revendo isso, nos dá um gás para nós seguirmos.” (E4)
}

As figuras 3 e 4 dizem respeito às porcentagens referentes às turmas/anos em que os estágios foram realizados. Nos estágios 1, realizados na disciplina de Ciências do Ensino Fundamental há uma distribuição equilibrada, ficando com maior representatividade os $6^{\circ}$ e $8^{\circ}$ anos, seguidos do $9^{\circ}$ e do $7^{\circ}$ ano, respectivamente. Há o registro de um estágio realizado em turmas multisseriada, uma realidade ainda presente nas escolas do campo: segundo dados da Secretaria de Educação Continuada, 
Alfabetização e Diversidade e Inclusão - SECADI (2013), existe ainda no território nacional mais de 50 mil escolas multisseriadas no campo.

Essa expressiva quantidade traz à tona a necessidade de estabelecer políticas de formação de professores/as voltadas ao atendimento dessa especificidade pedagógica (JANATA; ANHAIA, 2015). Nos estágios do Ensino Médio há uma divisão igualitária entre $1^{\circ}$ ano (48\%) e $2^{\circ}$ ano (48\%), e sendo registrada apenas uma turma de $3^{\circ}$ ano (4\%). Um dos desafios do estágio do Ensino Médio da EduCampo/UFRGS é o incentivo à realização do estágio, de forma interdisciplinar e concomitante, nas três disciplinas das Ciências da Natureza (Química, Física e Biologia), em consonância com a proposta de formação por área de conhecimento.

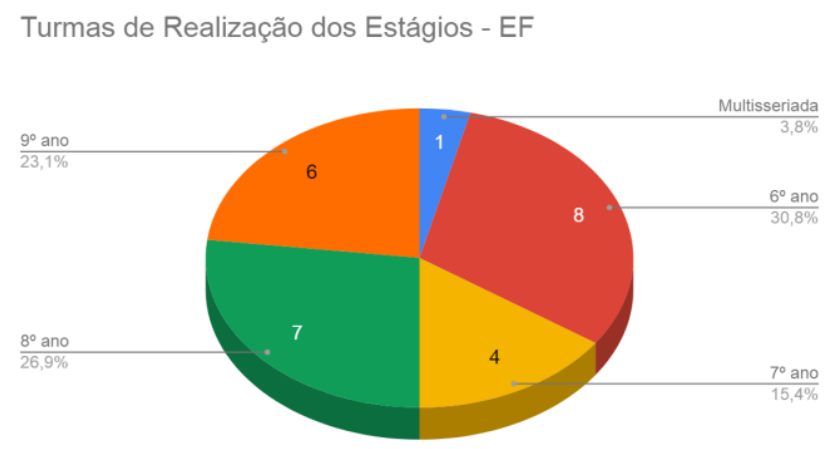

Figura 3: Turmas de realização dos estágios- Ensino Fundamental Fonte: dos autores, 2019.

Turmas de Realização dos Estágios -EM

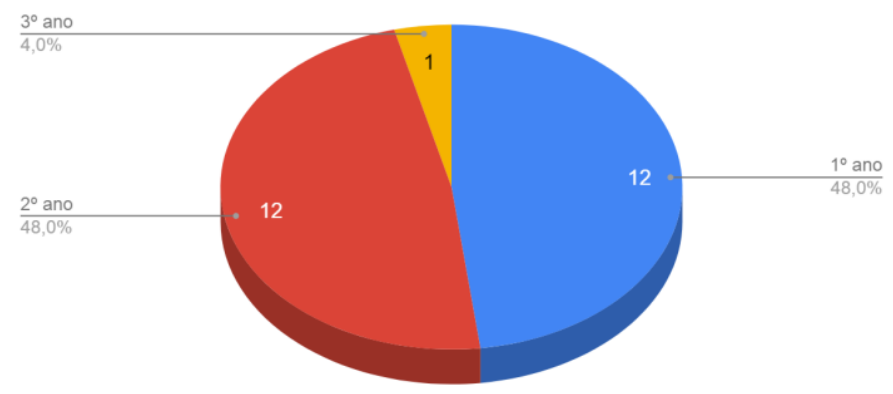

Figura 4: Turmas de realização dos estágios- Ensino Médio Fonte: dos autores, 2019. 
Na figura 5, é possível verificar os municípios em que os estágios são realizados, sendo muitos deles, o local em que os estudantes são provenientes ou que moram próximo. O reconhecimento dos locais dos estágios, no contexto da Educação do Campo se faz ainda mais importante ao considerar as questões referentes à acesso, transporte, distâncias e pertencimento aos locais de estágio, pois tudo isso interfere tanto na rotina dos professores que lá atuam, como também na rotina dos estagiários.

\section{Escolas por Município de realização dos Estágios}

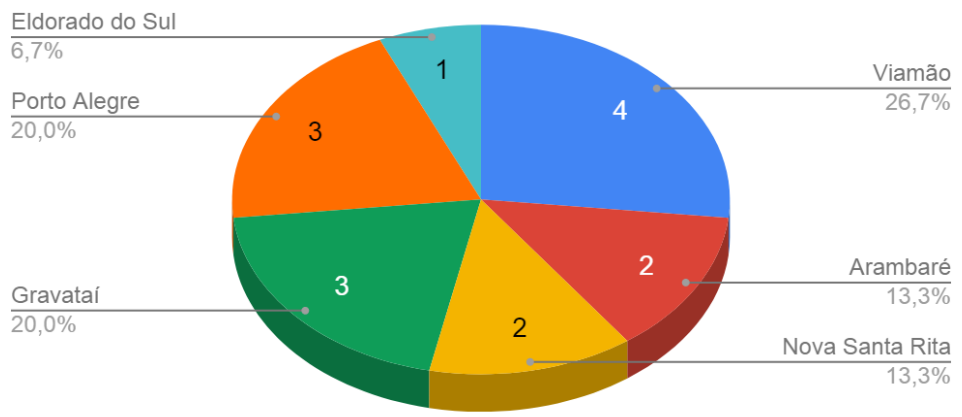

Figura 5: Escolas por município de realização dos estágios

Fonte: dos autores, 2019.

Desse modo, é aconselhável que o momento do estágio de docência seja a continuidade das atividades que já vinham sendo realizadas no Tempo-Comunidade desde o início do curso, minimizando dificuldades das mais variadas ordens, como falta de conhecimento da realidade local e de identificação com as demandas da comunidade. Sobre o reconhecimento do curso nas comunidades e escolas da região de abrangência do curso, os professores/as E2, E3 e E5 pontuam que:

\footnotetext{
"Não, não conhecia [o curso]. Até sabia que tinha uma área mais voltada para o Campo. E, no meu parecer, eu achei uma boa, principalmente pela localidade e pelo público que a gente tem aqui nessa área. Uma vez que tenha que estudar algo que esteja acessível aos alunos, que sejam da realidade deles." (E3, grifos nossos)
}

"Não conhecia o curso, conheci com o pessoal, seus colegas. É uma abordagem diferente da graduação que recebi." (E2)

A entrevistada E3 pontuou a dificuldade em aplicar, no contexto real da escola, as práticas interdisciplinares preconizadas no curso: 
"Concordo com a interdisciplinaridade, está tudo conectado, mas na realidade dos educandos, que são do modo engavetado é um desafio.” (E3)

A fala da professora revela um desafio que os cursos de formação de professores na Educação do Campo, por área do conhecimento, enfrentam cotidianamente. Apesar da formação interdisciplinar estar presente em toda sua essência e prática, a força da tradição das áreas disciplinares de origem (no caso das Ciências da Natureza, da química, física e biologia), ao mesmo tempo que não podem ser negligenciadas, se mostram muitas vezes como um impasse ao diálogo, tanto na escola quanto na docência universitária. Sobre o tema, Brick et al. (2014) argumentam que:

[...] é um processo formativo complexo e difícil de se pôr em prática, visto que parte considerável dos docentes que atuam na educação superior são oriundos de processos formativos extremamente fragmentados, com pouco ou quase nenhum diálogo entre as disciplinas de uma mesma área em sua própria formação. [...] $\mathrm{O}$ que se busca alcançar é a ação interdisciplinar na qual a articulação entre os conhecimentos científicos se dê a partir realidade, de sua concretude e materialidade, e não a partir da abstração dos campos do conhecimento científico desprovidos das contradições. Intenciona-se promover ações interdisciplinares do real que contribuam com os educandos do campo para que sejam capazes de localizar, na realidade de suas ações, os diferentes campos do conhecimento científico que podem contribuir para ampliar sua compreensão de determinados fenômenos com os quais se deparam. (BRICK et al., 2014, grifos nossos)

Neste sentido, considera-se fundamental o conhecimento dos locais de atuação do curso para que, a partir da identificação das demandas existentes, possam ser delimitadas as ações futuras, como o próprio processo de estabelecimento do curso permanente na UFRGS. A figura 6 representa a diversidade de formação acadêmica dos/as professores/as supervisores que recebem os estagiários nas escolas. Apesar de todos os estágios serem realizados nas disciplinas da área de Ciências da Natureza, percebe-se formações de outras áreas, como Educação Física, Pedagogia, História, Matemática e Agronomia. 


\section{Formação dos Professores Supervisores}

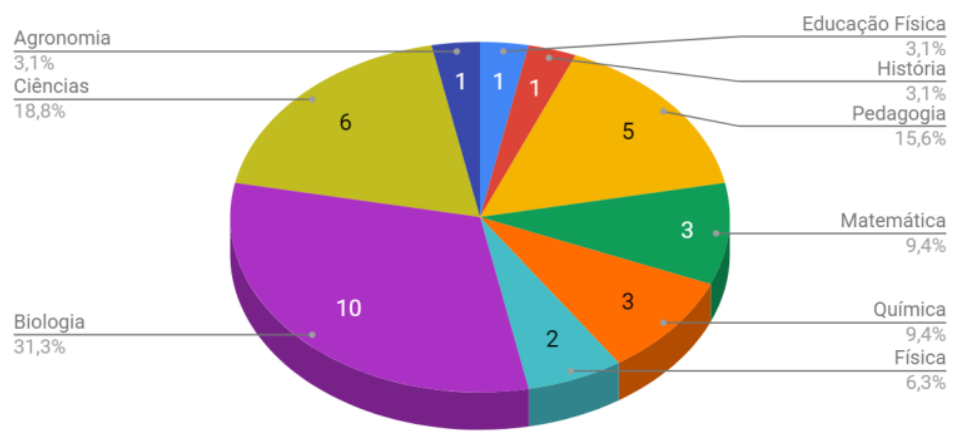

Figura 6: Formação dos professores supervisores dos estágios da área de Ciências da Natureza Fonte: dos autores, 2019.

Esse dado faz reforçar a importância e necessidade de formação inicial e continuada aos professores/as das redes de ensino, em especial, nas escolas do campo. Devido às distâncias e dificuldades de acesso, essas escolas acabam por enfrentar falta de docentes com formação nas áreas específicas, que não conseguem cumprir a carga horária mínima se dividindo em várias escolas.

\section{CONSIDERAÇÕES FINAIS}

O levantamento dos dados referentes ao território de atuação da EduCampo/ UFRGS permitiu mapear com maior objetividade os locais em que a licenciatura já se encontra inserida e de que forma, seja pelas atividades do Tempo-Comunidade, pelos estágios de docência ou por projetos de pesquisa e extensão dos docentes. Também foi possível verificar a necessidade, ainda, de uma maior articulação com outros municípios da região de abrangência, que dê conta da diversidade de povos, comunidades e movimentos sociais do campo.

Ao término desta pesquisa, conclui-se que os objetivos foram atingidos, no sentido de obtermos um panorama das escolas, dos/as professores/as e das instituições de atuação da Licenciatura em Educação do Campo da UFRGS campus Porto Alegre. Este conjunto foi mapeado, organizado e disponibilizado de modo on line no site da Licenciatura em Educação do Campo e, hoje, encontra-se disponível à comunidade acadêmica e externa para consultas. Do mesmo modo, foi possível uma maior aproximação com as escolas e os 
docentes supervisores dos estágios, sendo que, além da obtenção do perfil profissional, foi possível desvelar e compreender alguns de seus anseios, dificuldades, desafios cotidianos de suas docências e suas compreensões em relação à Licenciatura em Educação do Campo.

Algo que chamou atenção foi o desconhecimento, por parte dos/as professores/as das escolas, da Licenciatura em Educação do Campo e de seus objetivos e formações de egressos, fato que destaca um desafio a ser enfrentado pela universidade no sentido de disseminar, entre as instituições de ensino, esta modalidade de ensino e a atuação dos futuros professores que estão se formando na área de Ciências da Natureza. Há de se destacar também que os educadores percebem positivamente a inserção das(os) estagiárias(os) nas escolas o que demonstra a importância de que o curso e a universidade avancem na atuação nos territórios.

Merece destaque também o pouco reconhecimento, entre os docentes e escolas, da educação do campo tanto como movimento quanto como localização espacial, partindo do pressuposto que muitas das escolas, mesmo estando localizadas no meio rural, não se reconhecem como "do campo", não se identificam com seus princípios e, tampouco, almejam isso. Diante do atual contexto, de fechamento de escolas do campo, redução de verbas para a educação e tentativa de enfraquecimento dos movimentos sociais populares, esse quadro é algo que exige, mais do que nunca, a reflexão e ação da universidade e da Licenciatura em Educação do Campo, no sentido de unir esforços para que a identidade dos povos do campo e dos princípios da Educação do Campo enquanto movimento (agroecologia, sustentabilidade, organização coletiva, entre outros) estejam presentes e vivos.

\section{REFERÊNCIAS}

BRASIL. Decreto $\mathbf{n}^{\mathbf{0}} \mathbf{7 . 3 5 2}$, de 4 de Novembro de 2010. Dispõe sobre a política de educação do campo e o Programa Nacional de Educação na Reforma Agrária PRONERA. Edição federal, Brasília, 2010.

BRASIL. Resolução n⿳ 2, de 28 de Abril de 2008. Estabelece diretrizes complementares, normas e princípios para o desenvolvimento de políticas públicas de atendimento da Educação Básica do Campo. Edição federal, 2010.

BRICK, E. et al. Paulo Freire: interfaces entre Ensino de Ciências Naturais e Educação do Campo. In: Licenciaturas em Educação do Campo e o ensino de Ciências Naturais: desafios à promoção do trabalho docente interdisciplinar/Mônica Castagna Molina, org. - Brasília: MDA, 2014. 
CALDART, R. S. Caminhos para transformação da escola: reflexões desde práticas da licenciatura em educação do campo./organização Roseli Salete Caldart: textos Andréa Rosana Fetzner...et al. - 1 .ed. - São Paulo: Expressão Popular, 2011. 248p: grafs.

CALDART, R. Desafios de consolidação da Licenciatura em Educação do Campo. Texto de abertura do Seminário 10 anos da Licenciatura em Educação do Campo. Planaltina, UnB, 23 a 27 de Outubro 2017.

HOFFMANN, M.B. Constituição da identidade profissional docente dos formadores de professores de biologia: potencialidades de Intercoletividade/ Tese de Doutorado. Programa de Pós-graduação em Educação Científica e Tecnológica. Florianópolis, SC, 2016. 315 p.

INEP. Estatísticas da Educação Básica. Disponível em: <http://portal.inep.gov.br/sinopses-estatisticas-da-educacao-basica> Acesso em: $01 \mathrm{de}$ Maio de 2019.

JANATA, N.; ANHAIA, E. M. Escolas/Classes Multisseriadas do Campo: reflexões para a formação docente. Educação \& Realidade, Porto Alegre, 2015. Disponível em: $<$ http://www.scielo.br/pdf/edreal/2015nahead/2175-6236-edreal-45783.pdf>. Acesso em: 30 de Outubro de 2018.

LUDKE, M.. ANDRE, M. Pesquisa Em Educação - Abordagens Qualitativas - $2^{\text {a }}$ Ed. São Paulo: EPU, 2013.

MANZINI, E.J. Considerações sobre a elaboração de roteiro para entrevista semiestruturada. In: MARQUEZINE: M. C.; ALMEIDA, M. A.; OMOTE; S. (Orgs.) Colóquios sobre pesquisa em Educação Especial. Londrina: Eduel, 2003.

MOLINA, M. Licenciaturas em Educação do Campo e o ensino de Ciências Naturais: desafios à promoção do trabalho docente interdisciplinar./Mônica Castagna Molina, org. - Brasília: MDA, 2014. 268 p. (Série NEAD Debate; 23).

MOLINA, M.C. ANTUNES-ROCHA, M. I. Educação do Campo: História, práticas e desafios no âmbito das políticas de formação de educadores - reflexões sobre o Pronera e o Procampo. Revista Reflexão e Ação, Santa Cruz do Sul, v.22, n.2, p. 220-253, jul./dez.2014.

MOLINA, M. C. Contribuições das Licenciaturas em Educação do Campo nas políticas de formação de educadores. Educ. Soc., Campinas, v. 38, nº 140, p.587-609, jul.-set., 2017. Disponível em: <http://www.scielo.br/pdf/es/v38n140/1678-4626-es-38-14000587.pdf $>$. Acesso em: 30 de Outubro de 2018.

MUNARIM, Antonio. Trajetória do movimento nacional de educação do campo no Brasil. Revista do Centro de Educação. Edição: 2008, vol. 33, nº 01.

RIO GRANDE DO SUL. Lei $\mathbf{n}^{\mathbf{0}}$ 14.705, de 25 de Junho de 2015. Institui O Plano Estadual de Educação - PEE - , em cumprimento ao Plano Nacional de Educação - PNE - , aprovado pela Lei Federal n. ${ }^{0}$ 13.005, de 25 de junho de 2014. Edição federal, 2014.

RIO GRANDE DO SUL. Decreto no 49.861, de 22 de Novembro de 2012. Institui o 
Comitê Estadual de Educação do Campo do Estado do Rio Grande do Sul. Porto Alegre, 2012.

SECRETARIA DA EDUCAÇÃO DO RS. Educação do Campo. Disponível em: <http://www.educacao.rs.gov.br/escolas-do-campo-5898a9534630b>. Acesso em: 30 de Outubro de 2018.

UFRGS. Projeto Político Pedagógico da Licenciatura em Educação do CampoCiências da Natureza. 2013. 